BNL-52650

Formal Report

\title{
Sulfur Polymer Stabilization/Solidification (SPSS) Treatability of Los Alamos National Laboratory Mercury Waste
}

\author{
J.W. Adams and P.D. Kalb
}

November 2001

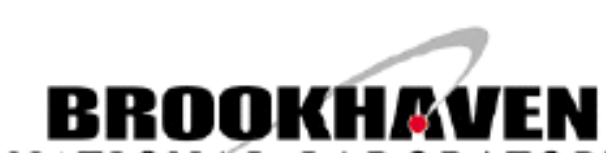 \\ NATIONAL LABORATORY}

Environmental Sciences Department

Brookhaven National Laboratory

Brookhaven Science Associates

Upton, Long Island, New York 11973

Under Contract No. DE-AC02-98CH10886 with the

UNITED STATES DEPARTMENT OF ENERGY 


\section{Disclaimer}

This report was prepared as an account of the work sponsored by an agency of the United States Government. Neither the United States Government nor any agency thereof, nor any of their employees, nor any of their contractors, subcontractors or their employees, makes any warranty, express or implied, or assumes any legal liability or responsibility for the accuracy, completeness, or any third party's use or the results of such use of any information, apparatus, product, or process disclosed, or represents that its use would not infringe privately owned rights. Reference herein to any specific commercial product, process, or service by trade name, trademark, manufacturer, or otherwise, does not necessarily constitute or imply its endorsement, recommendation, or favoring by the United States Government or any agency thereof, or its contractors or subcontractors. The views and opinions of authors expressed herein do not necessarily state or reflect those of the United States Government or any agency thereof. 


\title{
Sulfur Polymer Stabilization/Solidification (SPSS) Treatability of Los Alamos National Laboratory Mercury Waste
}

\author{
J.W. Adams and P.D. Kalb
}

November 2001

\author{
Work Conducted for \\ U.S. Department of Energy \\ Office of Science and Technology \\ Mixed Waste Focus Area
}

Work Conducted by

Environmental Research and Technology Division

Department of Environmental Science

Brookhaven National Laboratory

Upton, NY 11973

*This work was performed under the auspices of the U .S. D epartment of Energy. 



\begin{abstract}
Brookhaven National Laboratory's Sulfur Polymer Stabilization/Solidification (SPSS) process was used to treat approximately $90 \mathrm{~kg}$ of elemental mercury mixed waste from Los Alamos National Laboratory. Treatment was carried out in a series of eight batches using a $1 \mathrm{ft}^{3}$ pilot-scale mixer, where mercury loading in each batch was 33.3 weight percent. Although leach performance is currently not regulated for amalgamated elemental mercury (Hg) mixed waste, Toxicity Characteristic Leach Procedure (TCLP) testing of SPSS treated elemental mercury waste indicates that leachability is readily reduced to below the TCLP limit of $200 \mathrm{ppb}$ (regulatory requirement following treatment by retort for wastes containing > $260 \mathrm{ppb} \mathrm{Hg}$ ), and with process optimization, to levels less than the stringent Universal Treatment Standard (UTS) limit of $25 \mathrm{ppb}$ that is applied to waste containing < $260 \mathrm{ppm} \mathrm{Hg}$. In addition, mercury-contaminated debris, consisting of primary glass and plastic containers, as well as assorted mercury thermometers, switches, and labware, was first reacted with SPSS components to stabilize the mercury contamination, then macroencapsulated in the molten SPSS product. This treatment was done by vigorous agitation of the sulfur polymer powder and the comminuted debris. Larger plastic and metal containers were reacted to stabilize internal mercury contamination, and then filled with molten sulfur polymer to encapsulate the treated product.
\end{abstract}




\section{TABLE OF CONTENTS}

Page

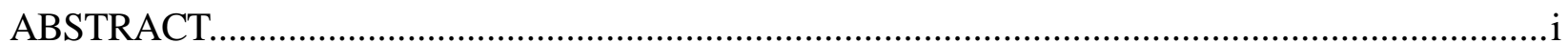

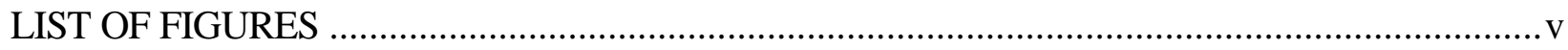

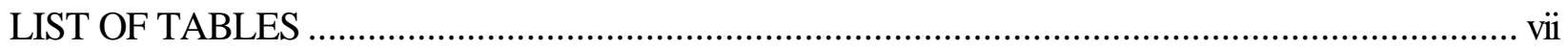

1. INTRODUCTION

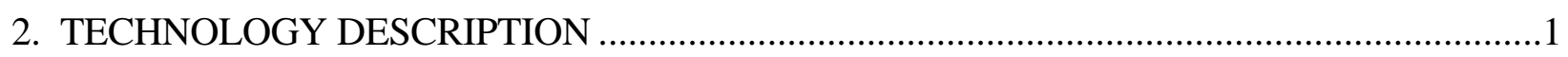

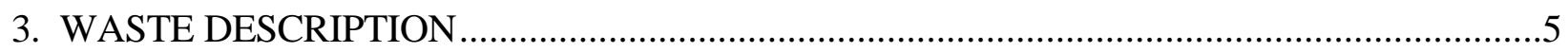

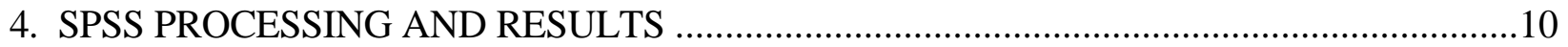

4.1 Treatment of Elemental Mercury Waste …………............................................................. 10

4.2 Treatment of Contaminated Labware/Containers................................................................17

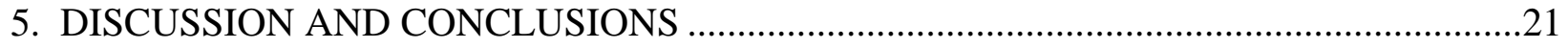

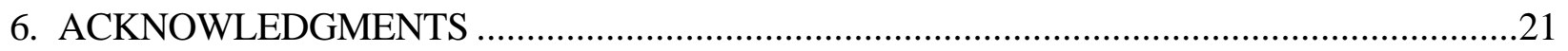

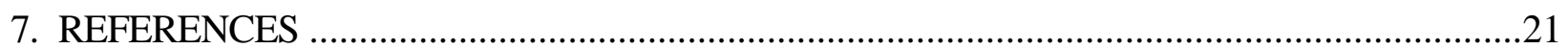




\section{LIST OF FIGURES}

Page

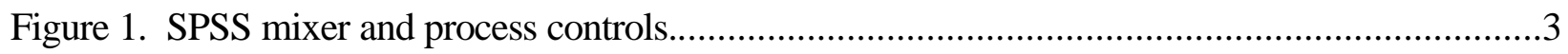

Figure 2. Internal view of Ross Vertical Cone Mixer. ................................................................

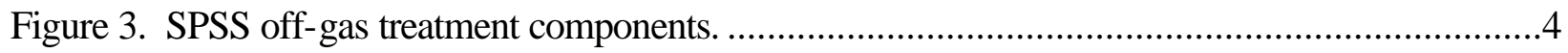

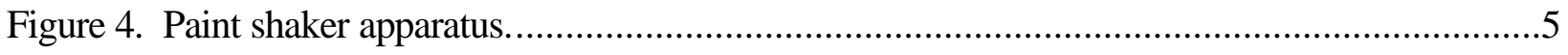

Figure 5. Vacuum apparatus used to pump mercury from iron flasks..................................................

Figure 6. SPSS grab samples from LANL mixed-waste mercury process batches. ............................15

Figure 7. LANL Hg/SPSS pellets for TCLP testing.................................................................16

Figure 8. Crushed LANL glassware prior to SPSS treatment.....................................................18

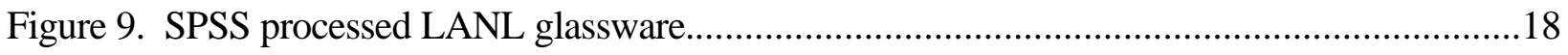

Figure 10. Size-reduced LANL plasticware.............................................................................19

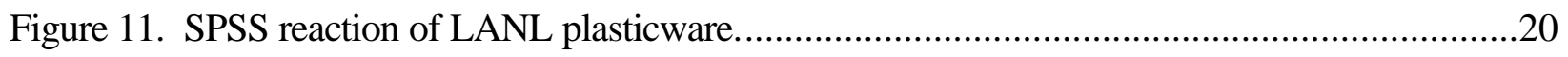

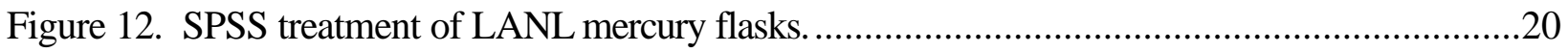




\section{LIST OF TABLES}

Page

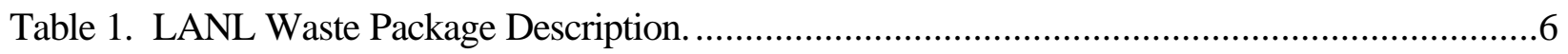

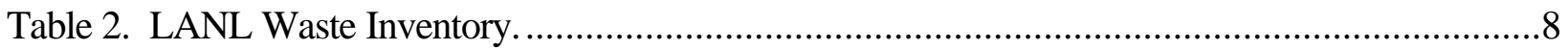

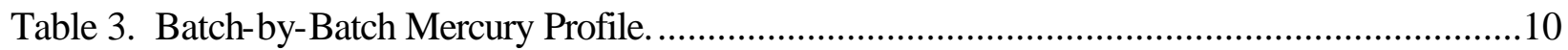

Table 4. TCLP Hg Results for SPSS Treated LANL Elemental Mercury Waste................................17 


\section{INTRODUCTION}

Los Alamos National Laboratory (LANL) has over $3600 \mathrm{~kg}$ of mercury waste for which they are seeking an effective and economical method of treatment. These legacy wastes, currently in storage, are primarily elemental (liquid) mercury contaminated with radionuclides (mixed waste), along with mercury-contaminated glassware and containers, some dating to weapons testing of decades ago. The primary radiological contaminants of concern are Tc-99, Th-232, U-238, H-3, Pu-239, Cs-137, Sr-90, and U-235.

This study investigated application of Brookhaven National Laboratory's Sulfur Polymer Stabilization/Solidification (SPSS) process for treatability of LANL mercury-contaminated waste. In the SPSS process, mercury is reacted with powdered sulfur polymer cement (a thermoplastic material composed of $95 \mathrm{wt} \%$ elemental sulfur) to form a stable mercury sulfide compound with significantly reduced leachability and lower vapor pressure. The reacted mixture is then melted, mixed, and cooled to form a monolithic solid waste form in which the stabilized mercury particles are microencapsulated within a sulfur polymer matrix. The resultant material meets Environmental Protection Agency (EPA) criteria for amalgamation (AMLGM) treatment of elemental mixed-waste mercury (Hg), allowing the waste to be declassified as a hazardous material.

Approximately $90 \mathrm{~kg}(200 \mathrm{lb})$ of mixed-waste elemental mercury was received from LANL in assorted glass, plastic, and metal containers. Elemental mercury waste was treated in a pilot-scale, batchwise process, and subjected to leachability testing to benchmark performance. Mercury-contaminated containers were also reacted and encapsulated.

\section{TECHNOLOGY DESCRIPTION}

Sulfur Polymer Stabilization/Solidification (SPSS) is based on Sulfur Polymer Microencapsulation, a patented mixed-waste treatment technology previously developed at BNL. ${ }^{1}$ Sulfur Polymer Cement (SPC) consists of $95 \mathrm{wt} \%$ elemental sulfur reacted with $5 \mathrm{wt} \%$ of an organic modifier to enhance mechanical integrity and long-term durability. Previous testing conducted on sulfur polymer waste forms indicates excellent performance under anticipated disposal conditions. ${ }^{2,3}$ During FY97, SPSS was demonstrated at the Brookhaven National Laboratory Environmental \& Waste Technology Center (BNLEWTC), as part of a Department of Energy Mixed Waste Focus Area (DOE MWFA) Quick Win Project, and used to treat the entire $24.5 \mathrm{Kg}$ inventory of BNL mixed-waste elemental mercury. ${ }^{4}$ In FY98, two 55 gallon drums of mixed-waste $\mathrm{Hg}$ contaminated soils and $68 \mathrm{~kg}$ of mixed-waste elemental $\mathrm{Hg}$ excavated from the BNL Chemical Holes were successfully treated. ${ }^{5}$ Newmont Mining, Inc. recently licensed SPSS for productionscale use on elemental $\mathrm{Hg}$ generated in gold mining operations. 
SPSS mercury treatment (patent pending) is conducted in two stages. The first step is a reaction between mercury and powdered SPC, forming mercuric sulfide, as seen in Equation 1:

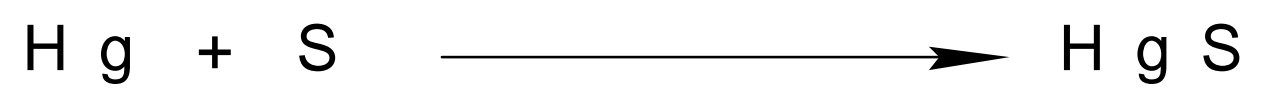

The second step involves melting the thermoplastic sulfur binder. On cooling, the reacted sulfide particles become microencapsulated within the inert sulfur matrix. Since the BNL SPSS process includes chemical stabilization of the mercury yielding mercury sulfide, it meets EPA requirements for AMLGM.

Bench-scale development work for the SPSS process demonstrated that as much as $33 \mathrm{wt} \%$ elemental mercury could be successfully encapsulated and would still meet EPA Toxicity Characteristic Leach Procedure (TCLP) leaching criteria. ${ }^{6}$ This ratio assures nearly a 12-fold molar excess of sulfur to mercury, facilitating a fast reaction of the mercury metal with sulfur. A small quantity (up to $2 \mathrm{wt} \%$ of additive is included to ensure the sulfide reaction). During reaction the vessel is placed under inert gas (nitrogen) atmosphere to prevent the formation of mercuric oxide (a water soluble and highly leachable compound); also, the vessel is heated to $\sim 40^{\circ} \mathrm{C}$ to enhance sulfide formation. Once the mercury is chemically stabilized, the mixture is heated at about $130^{\circ} \mathrm{C}$ until a homogeneous molten mixture is formed. It is then poured into a suitable mold where it cools to form a monolithic solid waste form.

Pilot-scale SPSS processing was accomplished using a $1-\mathrm{ft}^{3}$ oil-heated vertical cone mixer (Ross Mixers, Hauppauge, NY). Mixing action is provided by a 24 inch long auger screw, rotating up to $105 \mathrm{rpm}$, which also revolves orbitally around the wall of the vessel, at up to $2.5 \mathrm{rpm}$. Feed materials are charged to the unit through a 6-inch diameter port on the cone lid with the auger screw drawing material upward from the base of the cone. A photograph of the mixer and associated process controls is shown in Figure 1. The interior of the process vessel is shown in Figure 2. When mixing or drying, the system may be evacuated to up to 22 " $\mathrm{Hg}$, or purged with an inert gas by connection to a regulated nitrogen gas supply. Heat is provided to the jacketed cone by a $9 \mathrm{~kW}$ circulating fluid heat transfer system (Mokon, Buffalo, NY). A $5 \mathrm{~cm}$ (2 in) heated ball valve at the base of the cone was used to discharge the molten SPSS product. 


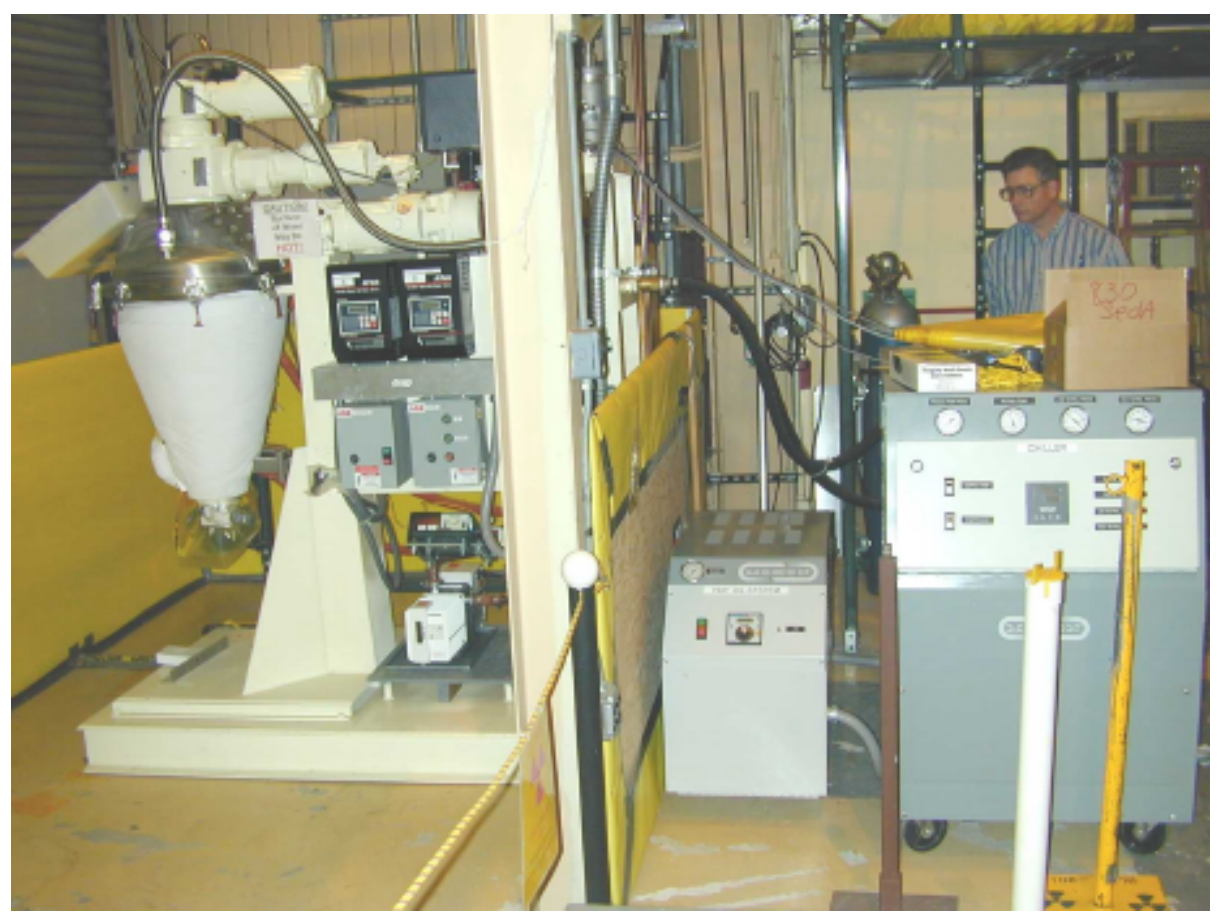

Figure 1. SPSS mixer and process controls.

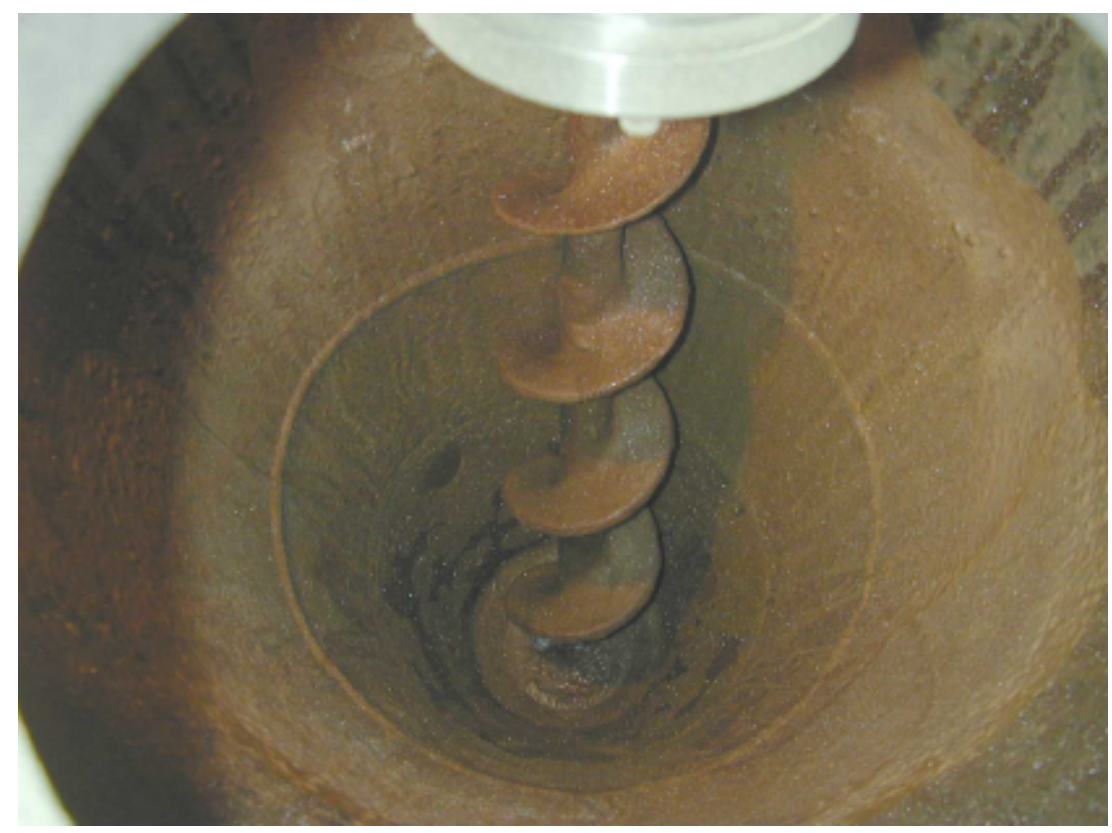

Figure 2. Internal view of Ross Vertical Cone Mixer. 
Off-gas is captured in multiple stages: first it passes through a shell and tube heat exchanger cooled by a 3 ton chiller (Mokon), followed by a liquid nitrogen cryogenic trap, and finally through HEPA and activated charcoal filters before venting to the atmosphere. Condensate is drained from the heat exchanger and collected in a 6" diameter x 36" tall Lucite vessel; the cryogenic trap collects residual vapor that may escape the water-cooled trap. Figure 3 shows the off-gas components mounted at the rear of the process vessel.

For SPSS processing of contaminated LANL debris, a 5 gallon heated-drum shaker was utilized. A 5 gallon heavy-gauge steel shipping drum was used as a reaction vessel for crushed glass and plasticware. Empty metal mercury flasks were similarly clamped to the shaker to react residual mercury contamination within. Where desired, the metal vessels were wrapped with heat tape to allow controlled heating of the vessel and its contents while shaking. A photograph of the paint shaker apparatus is shown in Figure 4.

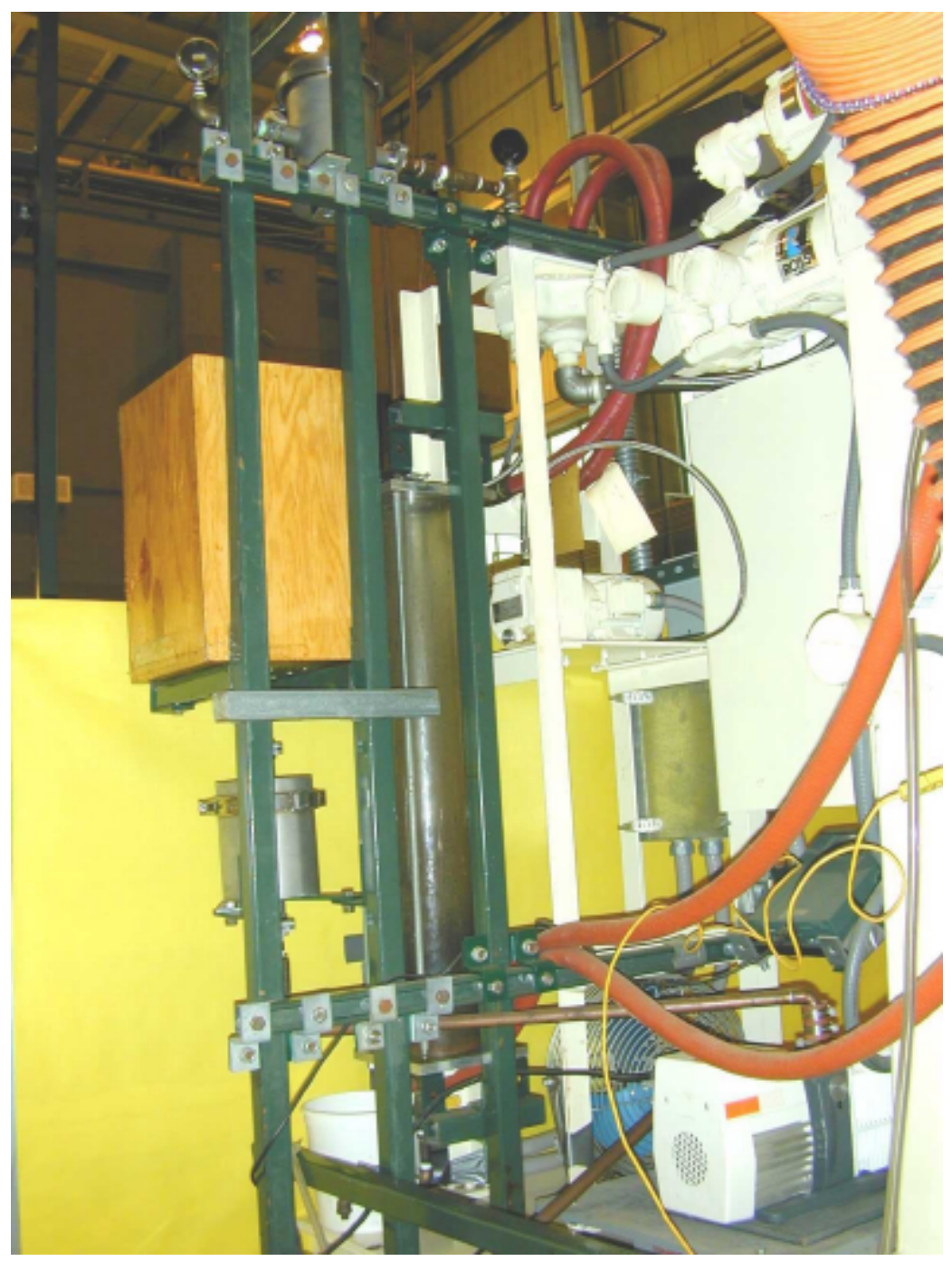

Figure 3. SPSS off-gas treatment components. 


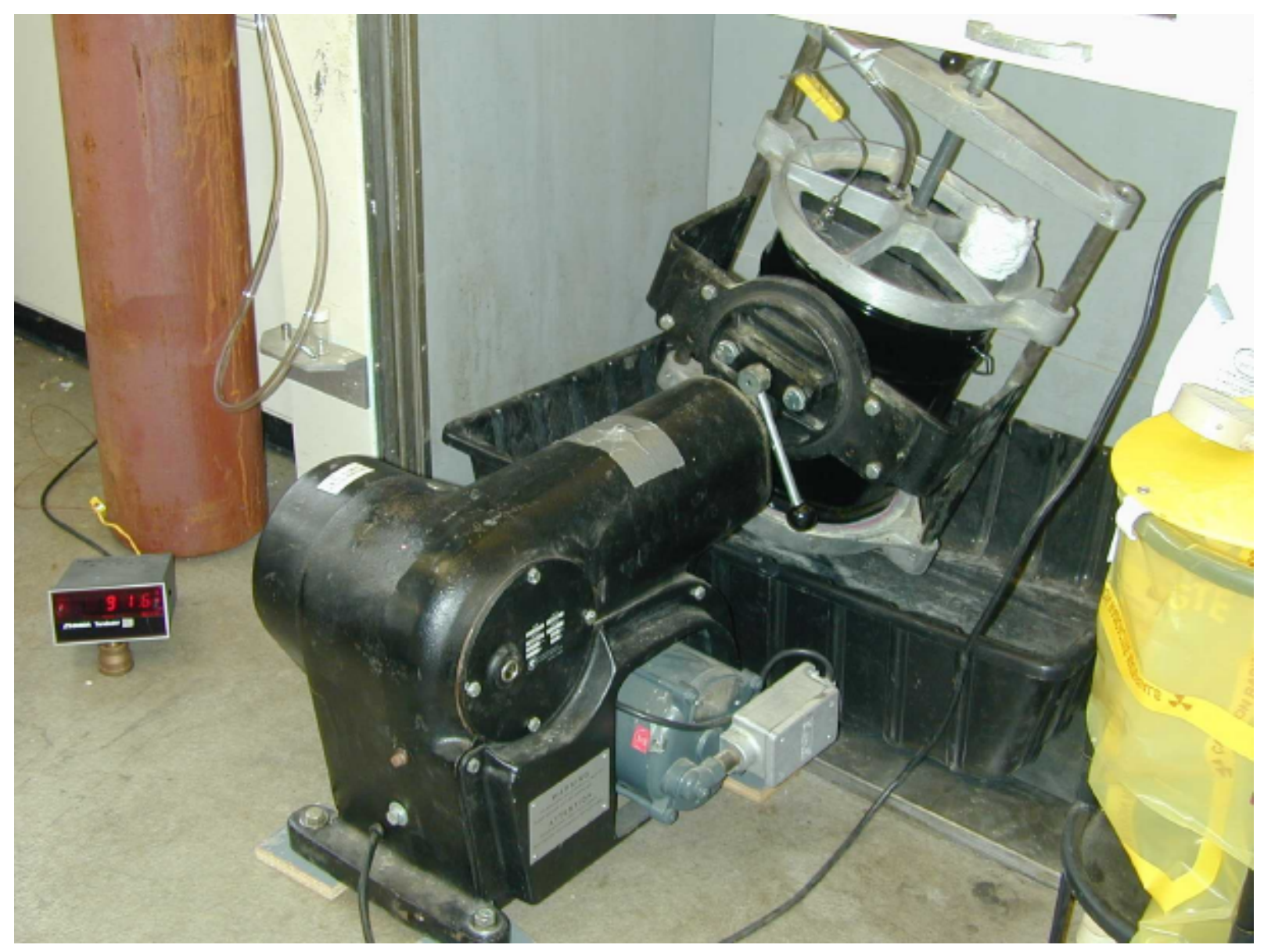

Figure 4. Paint shaker apparatus.

\section{WASTE DESCRIPTION}

LANL waste was received in five overpack containers: three 30-gal steel drums, one 14 gal polyethylene drum, and one 5 gal plastic bucket. Within the overpacks the waste shipment was divided into five "packages", consisting of assorted containers filled with mercury, mercury-contaminated articles, or mercury cleanup debris, such as cloth, PPE, wipes, and plastic. Itemized descriptions of the five LANL waste packages are given in Table 1 . 


\section{Table 1. LANL Waste Package Description}

Package \# 1 - 14 gal. Poly

901154 - Item \# 1010897

1010898

1023954

Weight - 133lbs (estimate - flask and $\mathrm{Hg}$ )

3 flasks filled mercury. Flasks were packed in green absorbent.

Package \# 2 - 30 gal metal

C97094977 - Item \# 2072778 - large Nalgene container with Hg 1.5inches from bottom - 20430g

Added to above drum - 2 paint cans

- C92028822 - item \# 13580 - glass bottle $1 / 4$ fill w/ Hg - 1003.4g

- C96065592 - item \# 2043755 - bottles and baggie were placed back into original paint can 4 bottles - estimate weights: $1.7 \mathrm{Kg}, 1.7 \mathrm{Kg}, 1.7 \mathrm{Kg}, 2.0 \mathrm{Kg}$ 1 baggie $-12.7 \mathrm{~g}$

\section{Package \# 3 - 5 gal pail}

C91024589 - Item \# 6179 - small plastic bottle $\mathrm{Hg}$ switch - 55g

Item \# 6262 - plastic bottle 1/8 filled with Hg.- 505.6g

Added to above drum

- 902607 - Item \# 1003263 - several small bottles with Hg weights: $1.3 \mathrm{Kg}, 818 \mathrm{~g}, 322 \mathrm{~g}, 342 \mathrm{~g}, 360 \mathrm{~g}, 586 \mathrm{~g}, 1.7 \mathrm{Kg}$,

$1.9 \mathrm{Kg}$

Item \# 1003924 - amber bottle containing $\mathrm{Hg}$ from a switch weight: $2.3 \mathrm{Kg}$

All items were packed in a 5-gal pail with wood chips and vermiculite

Package \# 4 - 5 gal pail

C97099592 - Item \# 2088302 -broken thermometer wrapped in plastic - weight: 325g

Added to above drum

- C91023331 - Item \# 4761 - 3 plastic bottles each in their own plastic bag. weights: estimate $1.5 \mathrm{Kg}, 1.5 \mathrm{Kg}, 1.5 \mathrm{Kg}$

- C97097636 - Item \# 2083300 - unused small brown bottle of $\mathrm{Hg}$ in plastic bag -weight:963g 2083374 - larger glass container with $\mathrm{Hg}$ in plastic bag -weight: $1.7 \mathrm{Kg}$ 2083392 - the smaller container in plastic bag -weight: $187 \mathrm{~g}$

All items were packed into a 5 gal pail with vermiculite 


\section{Package \# 5 - 14 gal. Poly}

C92026076 - Item \# 8552 -2 small container w/ Hg and 2 baggies filled with small sampling vials of $\mathrm{Hg}$

Weights: Baggies - 1025g and 1702g; Small containers $-14 \mathrm{~g}$ and $39 \mathrm{~g}$

Item \# $8584-2$ small containers w/ Hg filled with $\mathrm{Hg}$

Weight : Small containers $-495 \mathrm{~g}$ and $1128 \mathrm{~g}$

Added to above drum

- 898080 - Item \# 1034897 - small jar of $\mathrm{Hg}$ - weight: 295g

- C93037582 - Item \# 25725 - this small container was in a plastic bag with what look like some loose

amalgamated Hg - weight: 2000g. This was packed into a paint can.

- 91001510 - Item \# 1022237 - small metal canister filled with clean up Hg debris such cloth, ppe, wipes

$$
\text { plastic - weight: } 535 \mathrm{~g}
$$

- Item \# 1022264 - larger metal canister filled with clean up Hg debris such cloth, ppe, wipes plastic - weight: $1.4 \mathrm{Kg}$

This was packed into a 14 gal poly drum with vermiculite.

With the overpack containers situated next to the hood as a precaution to ventilate mercury fumes in the headspace, secondary containers were removed from the packages following which individual primary containers, i.e., glass and plastic vials and bottles, were removed and weighed to verify the identity of each container. Item-by-item inventory logged for the shipment is shown in Table 2. Elemental (liquid) mercury aliquots from individual containers were then poured into one-liter wide mouth polyethylene containers so as to create batch quantities appropriate for SPSS pilot-scale processing. Bottles containing small quantities of elemental mercury were added together, or larger quantities split, so as to create individual batches weighing approximately $25 \mathrm{lb}(\sim 11.3 \mathrm{~kg})$. Mercury-contaminated solid debris (bottles used as primary containers for LANL elemental mercury and other mercury-contaminated debris) was segregated and bagged for subsequent size reduction/treatment using the paint shaker SPSS processing. 
Table 2. LANL Waste Inventory

\begin{tabular}{|c|c|c|c|c|c|c|c|c|c|c|c|c|c|}
\hline \multicolumn{5}{|c|}{ Radioactive Mercury Waste - D009 } & \multicolumn{9}{|c|}{ Radionuclides } \\
\hline Container ID & Item ID & Description & $\begin{array}{l}\text { Volume } \\
\left(\mathrm{cm}^{\wedge} 3\right)\end{array}$ & $\begin{array}{c}\text { Weight } \\
\text { (Kg) }\end{array}$ & $\begin{array}{l}\text { Total } \\
(\mathbf{C i})\end{array}$ & $\begin{array}{c}\text { Tc-99 } \\
(\mathbf{n C i} / g)\end{array}$ & $\begin{array}{l}\text { Th-232 } \\
(\mathrm{nCi} / \mathrm{g})\end{array}$ & $\begin{array}{c}\mathrm{U}-238 \\
(\mathrm{nCi} / \mathrm{g})\end{array}$ & $\mathrm{H}-3(\mathrm{nCi} / \mathrm{g})$ & $\begin{array}{l}\text { Pu-239 } \\
(\mathrm{nCi} / \mathrm{g})\end{array}$ & $\begin{array}{l}\mathrm{Cs}-137 \\
(\mathrm{nCi} / \mathrm{g})\end{array}$ & $\begin{array}{l}\text { Sr-90 } \\
(\mathrm{nCi} / \mathrm{g})\end{array}$ & $\begin{array}{c}\mathrm{U}-235 \\
(\mathrm{nCi} / \mathrm{g})\end{array}$ \\
\hline C970099592 & [2088302] & $\begin{array}{l}\text { Mercury } \\
\text { Thermometers }\end{array}$ & 2000 & 0.2 & 2.08E-09 & $6.68 \mathrm{E}-03$ & $1.67 \mathrm{E}-03$ & $8.34 \mathrm{E}-04$ & & & & & \\
\hline 898080 & [1034897] & Stock grade mercury & 10 & 0.7 & $1.00 \mathrm{E}-13$ & & & $1.47 \mathrm{E}-07$ & & & & & \\
\hline 901154 & [1011897] & $\begin{array}{l}\text { Mercury from } \\
\text { broken McCloud }\end{array}$ & 2000 & 8.0 & $1.05 \mathrm{E}-10$ & & & $1.25 \mathrm{E}-08$ & 4.37E-06 & $2.5 \mathrm{E}-09$ & & & \\
\hline & [1023954] & & 2000 & 8.0 & & & & & & & & & \\
\hline C91023331 & [4761] & $\begin{array}{l}\text { Glassware from } \\
\text { Mercury experiments }\end{array}$ & 300 & 4.5 & 4.5E-04 & $1.00 \mathrm{E}+02$ & & & & & & & \\
\hline C91024589 & [6179] & $\begin{array}{l}\text { Mercury from } \\
\text { storage }\end{array}$ & 5 & 0.0 & $1.00 \mathrm{E}-13$ & & & & & & $1.07 \mathrm{E}-07$ & & \\
\hline & {$[6262]$} & & 300 & 0.9 & & & & & & & & & \\
\hline C92026076 & [8552] & $\begin{array}{l}\text { Mercury from sink } \\
\text { trap and small vials }\end{array}$ & 7600 & 2.2 & $2.00 \mathrm{E}-13$ & & & $8.71 \mathrm{E}-08$ & & & & & \\
\hline C92028822 & [13580] & $\begin{array}{l}\text { Mercury from a } \\
\text { toeppler pump }\end{array}$ & 18900 & 0.9 & $3.5 \mathrm{E}-11$ & & & & $3.86 \mathrm{E}-05$ & & & & \\
\hline C93037582 & [25725] & $\begin{array}{l}\text { Dirty mercury with } \\
\text { suspect rad }\end{array}$ & 500 & 3.6 & $1.00 \mathrm{E}-13$ & & & $2.76 \mathrm{E}-08$ & & & & & \\
\hline C97097636 & [2083300] & $\begin{array}{l}\text { Unused mercury } \\
\text { from storage }\end{array}$ & 10 & 0.5 & $1.76 \mathrm{E}-10$ & $1.16 \mathrm{E}-05$ & $2.91 \mathrm{E}-06$ & $1.45 \mathrm{E}-06$ & & & & & \\
\hline & [2083374] & & 200 & 10.0 & & & & & & & & & \\
\hline & [2083392] & & 10 & 0.5 & & & & & & & & & \\
\hline 902607 & [1003263] & $\begin{array}{l}\text { Mercury from } \\
\text { switch and storage }\end{array}$ & 70 & 0.7 & 4.5E-13 & & & & & & 2.34E-09 & 9.37E-09 & 9.37E-09 \\
\hline & [1003924] & & 1420 & 2.3 & & & & & & & & & \\
\hline & [1033479] & virtual $\mathrm{Hg}$ & & & & & & & & & & & \\
\hline C97094977 & [2072778] & $\begin{array}{l}\text { Tritium contaminated } \\
\text { mercury from } \\
\text { diffusion pumps }\end{array}$ & 190 & 20.2 & $6.62 \mathrm{E}-02$ & & & & $3.25 \mathrm{E}+03$ & & & & \\
\hline & [1022264] & & 60 & 7.2 & & & & & & & & & \\
\hline C96065592 & [2043755] & $\begin{array}{l}\text { four bottles of } \\
\text { mercury }\end{array}$ & 380 & 8.3 & 2.39E-08 & & & & $2.88 \mathrm{E}-03$ & & & & \\
\hline Totals & & & 37985 & 90.2 & 0.067 & & & & & & & & \\
\hline
\end{tabular}


Approximately one half of the total mass of elemental mercury for the shipment was contained in three $69 \mathrm{lb}$ Department of Transportation (DOT) mercury-shipping flasks. The structural integrity of these flasks, fabricated of iron and received in a severely corroded condition, were of some concern. Removal of the liquid mercury proved to be straightforward, however, as the threaded plugs on three metal mercury flasks were readily removed following soaking with penetrating oil. The contents were then pumped out of the flasks using a vacuum assembly shown in Figure 5. Contents of the flasks were sub-divided as described above, and the empty flasks were retained for subsequent treatment using the paint shaker apparatus.

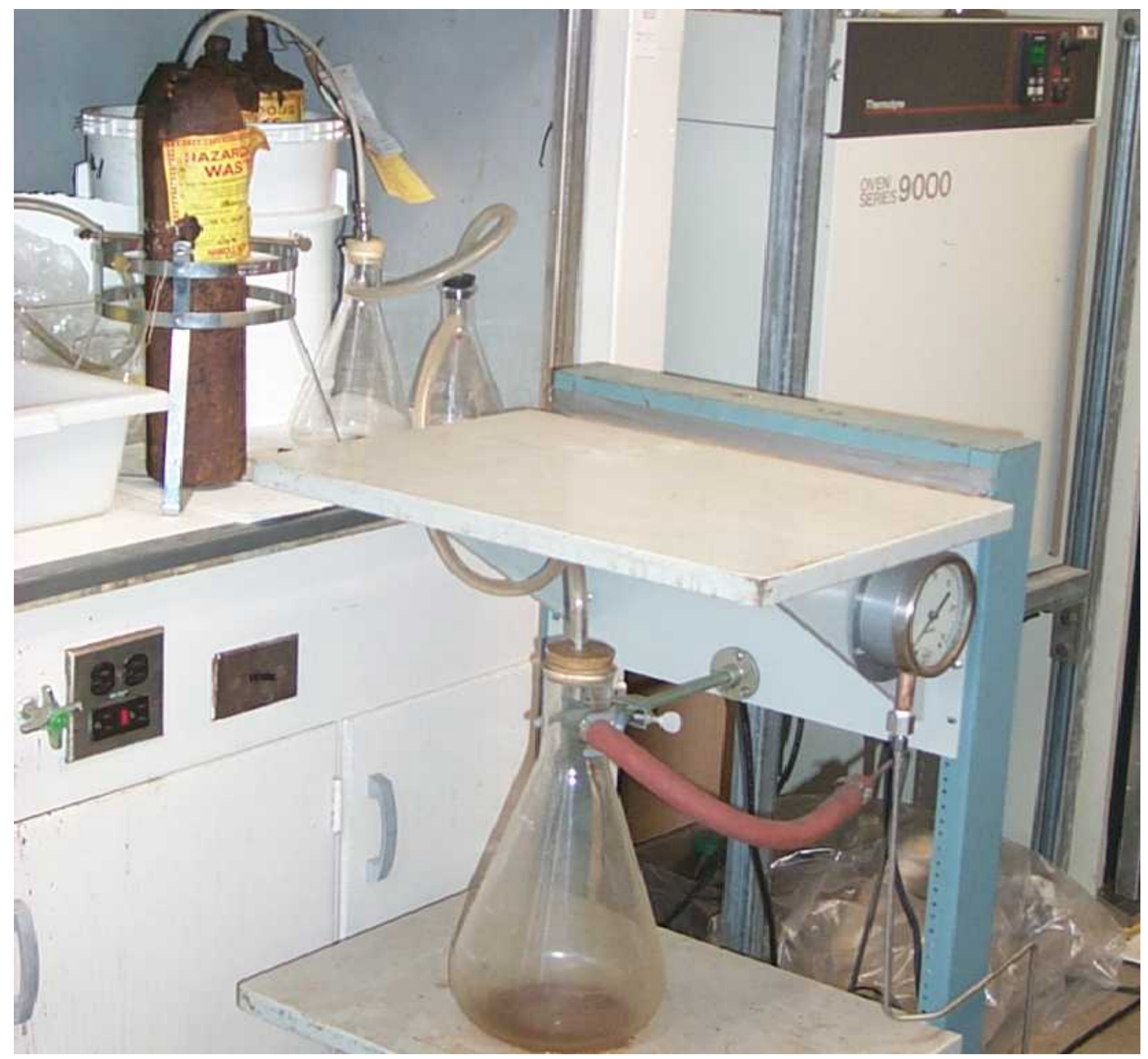

Figure 5. Vacuum apparatus used to pump mercury from iron flasks. 


\section{SPSS PROCESSING AND RESULTS}

\subsection{Treatment of Elemental Mercury Waste}

The actual weight of LANL elemental mercury, as accumulated in individual batch canisters, totaled 87.8 $\mathrm{kg}$. This inventory of was treated as eight separate SPSS process batches. Source and quantity of mercury for each individual batch, along with its radiological data, is shown in Table 3. Except for the final batch, all batches contained $11.35 \pm 0.01 \mathrm{~kg}$ mercury. The eighth batch contained $8.43 \mathrm{~kg}$ mercury.

Batches 1-7 were formulated based on a total weight of $75 \mathrm{lb}$. They consisted of $33.3 \mathrm{wt} \%$ (25.0 lb) mercury, $64.7 \mathrm{wt} \%(48.5 \mathrm{lb})$ sulfur polymer cement (SPC) powder, and $2.0 \mathrm{wt} \%(1.5 \mathrm{lb})$ dry additive. Batch 8 was scaled down due to the smaller mass of mercury; it consisted of $18.6 \mathrm{lb}$ of mercury and $36.1 \mathrm{lb}$ of SPC powder. For Batches 1 as well as Batches 3-8, additive in hydrated form was used (approximately $3 \mathrm{wt} \%$ of additive was included in each batch, however, as waters of hydration evolve during reaction/heating, the final formulation contained only $2 \mathrm{wt} \%$ additive). The hydrated form is instrumental in forming red cinnabar, thought to be the more stable form of $\mathrm{HgS}$. Batch 2 was processed using a dried form of additive after the drive shaft powering the auger mixing screw failed during the reaction phase mixing, allowing the reacted product to harden to a dry cake. After replacing the defective part (21 days later), the batch contents were manually chipped from the container and melted/encapsulated without further incident.

Batch \#1:

Table 3. Batch-by-Batch Mercury Profile

\begin{tabular}{|l|l|l|l|l|}
\hline Container ID & Item ID & Net Wt., g & Activity, Ci & Isotopes \\
\hline 902607 & 1003263 & 7839 & $4.50 \mathrm{e}-13$ & $\begin{array}{l}\text { Cs-137 }(2.34 \mathrm{e}-9 \mathrm{nci} / \mathrm{g}) \\
\text { Sr-90 }(9.37 \mathrm{e}-9 \mathrm{nci} / \mathrm{g}) \\
\text { U-235 }(9.37 \mathrm{e}-9 \mathrm{nci} / \mathrm{g})\end{array}$ \\
\hline 902607 & 1003924 & 1067 & $5.39 \mathrm{e}-14$ & $\begin{array}{l}\text { Cs-137 }(2.34 \mathrm{e}-9 \mathrm{nci} / \mathrm{g}) \\
\text { Sr-90 }(9.37 \mathrm{e}-9 \mathrm{nci} / \mathrm{g}) \\
\text { U-235 }(9.37 \mathrm{e}-9 \mathrm{nci} / \mathrm{g})\end{array}$ \\
\hline C91024589 & 6262 & 468 & $9.44 \mathrm{e}-14$ & Cs-137 (1.07e-7 nci/g) \\
\hline C92026076 & 8552 & 1988 & $9.68 \mathrm{e}-14$ & U-238 (8.71e-8 nci/g) \\
\hline Total & & $\mathbf{1 1 3 6 2}$ & $\mathbf{6 . 4 1 e - 1 3}$ & \\
\hline
\end{tabular}


Batch \#2:

\begin{tabular}{|l|l|l|l|l|}
\hline Container ID & Item ID & Net Wt., g & Activity, Ci & Isotopes \\
\hline C92028822 & 13580 & 844 & $3.50 \mathrm{e}-11$ & H-3 (3.86e-5 nci/g) \\
\hline C96065592 & 2043755 & 7565 & $2.39 \mathrm{e}-8$ & H-3 (2.88e-3 nci/g) \\
\hline C93037582 & 25725 & 1713 & $1.00 \mathrm{e}-13$ & U-238 (2.76e-8 nci/g) \\
\hline C92026076 & 8552 & 537 & $2.62 \mathrm{e}-14$ & U-238 (8.71e-8 nci/g) \\
\hline C92026076 & 8584 & 679 & $3.31 \mathrm{e}-14$ & U-238 (8.71e-8 nci/g) \\
\hline Total & & & $\mathbf{2 . 3 9 e - 8}$ & \\
& & & & \\
\hline
\end{tabular}

Batch \#3:

\begin{tabular}{|l|l|l|l|l|}
\hline Container ID & Item ID & Net Wt., g & Activity, Ci & Isotopes \\
\hline C97094977 & 2072778 & 11337 & $4.96 \mathrm{e}-2$ & $\mathrm{H}-3(3.25 \mathrm{e} 3 \mathrm{nCi} / \mathrm{g})$ \\
\hline Total & & $\mathbf{1 1 3 3 7}$ & $\mathbf{4 . 9 6 e - 2}$ & \\
& & & & \\
\hline
\end{tabular}


Batch \#4:

\begin{tabular}{|c|c|c|c|c|}
\hline Container ID & Item ID & Net Wt., g & Activity, Ci & Isotopes \\
\hline C97094977 & 2072778 & 3803 & $1.66 \mathrm{e}-2$ & $\mathrm{H}-3(3.25 \mathrm{e} 3 \mathrm{nCi} / \mathrm{g})$ \\
\hline C92026076 & 8584 & 895 & $4.36 \mathrm{e}-14$ & U-238 (8.71e-8 nCi/g) \\
\hline C92026076 & 8552 & 8 & $3.90 \mathrm{e}-16$ & U-238 (8.71e-8 nCi/g) \\
\hline 898080 & 1034897 & 180 & $1.00 \mathrm{e}-13$ & U-238 (1.47e-7 nCi $/ \mathrm{g})$ \\
\hline C97097636 & 2083374 & 1603 & $1.08 \mathrm{e}-10$ & $\begin{array}{l}\text { Tc-99 }(1.16 \mathrm{e}-5 \mathrm{nCi} / \mathrm{g}) \\
\text { Th-232 }(2.91 \mathrm{e}-6 \mathrm{nCi} / \mathrm{g}) \\
\text { U-238 }(1.45 \mathrm{e}-6 \mathrm{nCi} / \mathrm{g})\end{array}$ \\
\hline C97097636 & 2083300 & 837 & $5.65 \mathrm{e}-11$ & $\begin{array}{l}\text { Tc-99 }(1.16 \mathrm{e}-5 \mathrm{nCi} / \mathrm{g}) \\
\text { Th-232 }(2.91 \mathrm{e}-6 \mathrm{nCi} / \mathrm{g}) \\
\text { U-238 }(1.45 \mathrm{e}-6 \mathrm{nCi} / \mathrm{g})\end{array}$ \\
\hline C97097636 & 2083392 & 166 & $1.12 \mathrm{e}-11$ & $\begin{array}{l}\text { Tc-99 }(1.16 \mathrm{e}-5 \mathrm{nCi} / \mathrm{g}) \\
\text { Th-232 }(2.91 \mathrm{e}-6 \mathrm{nCi} / \mathrm{g}) \\
\mathrm{U}-238(1.45 \mathrm{e}-6 \mathrm{nCi} / \mathrm{g})\end{array}$ \\
\hline C91023331 & 4761 & 3854 & $3.84 \mathrm{e}-4$ & Tc-99 (1.00e2 nCi/g) \\
\hline Total & & 11346 & $1.70 \mathrm{e}-2$ & \\
\hline
\end{tabular}


Batch \#5:

\begin{tabular}{|l|l|l|l|l|}
\hline Container ID & Item ID & Net Wt., g & Activity, Ci & Isotopes \\
\hline 901154 & $*$ & 11340 & $2.85 \mathrm{e}-11$ & $\begin{array}{l}\text { U-238 }(1.25 \mathrm{e}-8 \mathrm{nCi} / \mathrm{g}) \\
\mathrm{H}-3(4.37 \mathrm{e}-6 \mathrm{nCi} / \mathrm{g}) \\
\mathrm{Pu}-239(2.50 \mathrm{e}-9 \mathrm{nCi} / \mathrm{g})\end{array}$ \\
\hline Total & & $\mathbf{1 1 3 4 0}$ & $\mathbf{2 . 8 5 e - 1 1}$ & \\
\hline
\end{tabular}

*The three metals flasks, items 1011897, 1010898, and 1023954, were not uniquely identifiable.

Batch \#6:

\begin{tabular}{|l|l|l|l|l|}
\hline Container ID & Item ID & Net Wt., g & Activity, Ci & Isotopes \\
\hline 901154 & $*$ & 11340 & $2.85 \mathrm{e}-11$ & $\begin{array}{l}\text { U-238 }(1.25 \mathrm{e}-8 \mathrm{nCi} / \mathrm{g}) \\
\mathrm{H}-3(4.37 \mathrm{e}-6 \mathrm{nCi} / \mathrm{g}) \\
\mathrm{Pu}-239(2.50 \mathrm{e}-9 \mathrm{nCi} / \mathrm{g})\end{array}$ \\
\hline Total & & $\mathbf{1 1 3 4 0}$ & $\mathbf{2 . 8 5 e - 1 1}$ & \\
\hline
\end{tabular}

*The three metals flasks, items 1011897, 1010898, and 1023954, were not uniquely identifiable.

Batch \#7:

\begin{tabular}{|c|c|l|l|l|}
\hline Container ID & Item ID & Net Wt., g & Activity, Ci & Isotopes \\
\hline 901154 & $*$ & 11341 & $2.85 \mathrm{e}-11$ & $\begin{array}{l}\text { U-238 }(1.25 \mathrm{e}-8 \mathrm{nCi} / \mathrm{g}) \\
\text { H-3 }(4.37 \mathrm{e}-6 \mathrm{nCi} / \mathrm{g}) \\
\text { Pu-239 }(2.50 \mathrm{e}-9 \mathrm{nCi} / \mathrm{g})\end{array}$ \\
\hline Total & & $\mathbf{1 1 3 4 1}$ & $\mathbf{2 . 8 5 e - 1 1}$ & \\
\hline
\end{tabular}

*The three metals flasks, items 1011897, 1010898, and 1023954, were not uniquely identifiable. 
Batch \#8:

\begin{tabular}{|l|l|l|l|l|}
\hline Container ID & Item ID & Net Wt., g & Activity, Ci & Isotopes \\
\hline 901154 & $*$ & 7739 & $1.95 \mathrm{e}-11$ & $\begin{array}{l}\text { U-238 }(1.25 \mathrm{e}-8 \mathrm{nCi} / \mathrm{g}) \\
\mathrm{H}-3(4.37 \mathrm{e}-6 \mathrm{nCi} / \mathrm{g}) \\
\text { Pu-239 }(2.50 \mathrm{e}-9 \mathrm{nCi} / \mathrm{g})\end{array}$ \\
\hline C91023331 & 4761 & 667 & $6.64 \mathrm{e}-5$ & Tc-99 $(1.00 \mathrm{e} 2 \mathrm{nCi} / \mathrm{g})$ \\
\hline C91024589 & 6179 & 28 & $5.65 \mathrm{e}-15$ & Cs-137 $(1.07 \mathrm{e}-7 \mathrm{nCi} / \mathrm{g})$ \\
\hline Total & & $\mathbf{8 4 3 4}$ & $\mathbf{6 . 6 4 e - 5}$ & \\
\hline
\end{tabular}

*The three metals flasks, items 1011897, 1010898, and 1023954, were not uniquely identifiable.

Procedure for adding, mixing, and melting components in the cone blender was standardized to yield consistent processing. To "lubricate" the walls of the mixer and enhance discharge of material, powdered SPC was added first such that an SPC-rich layer was created at the vessel wall. Liquid mercury waste was added in small, $10-20 \mathrm{ml}$ aliquots. To enhance dispersion of the liquid mercury, the waste was added while the screw was rotating, adding the liquid just prior to the advancing screw with each orbital rotation. Large and rapid addition of the mercury waste was avoided as the dense liquid would readily migrate and pool at the bottom of the cone mixer. After addition of the liquid mercury was complete, the ball valve at the base of the mixer was cracked to ensure all liquid mercury had been incorporated in the mix. The vessel was then evacuated and backfilled with nitrogen gas and the contents mixed for a minimum of 4 hours at $40 \pm 5^{\circ} \mathrm{C}$ to ensure sufficient reaction between the mercury and sulfur.

A small quantity of additive, used to enhance formation of mercuric sulfide, was included with each batch. The additive, in powder form, made up approximately $2 \mathrm{wt} \%$ of the final batch weight. Except for the second batch, where additive in dried form was used, the additive contained waters of hydration, which evolved during processing. Water in the additive was found to produce red cinnabar (mercury II sulfide, $\mathrm{HgS}$ ) during heating. Decreasing water in the mix, by using the dried form of additive or by removing water during processing, resulted in black cinnabar, thought to be slightly more leachable than the red form. As excessive amounts of hydrated additive resulted in water evolution during the reaction phase causing the mix to become wet, addition of this additive and extraction of water from the reacted product was varied batchto-batch, in attempts to optimize processing and product performance.

Following mixing, the vessel temperature was quickly increased to $135 \pm 5^{\circ} \mathrm{C}$ to melt the SPC and encapsulate the chemically stabilized mercury waste. Melting occurred within 30 minutes, after which time the molten mixture was mixed for approximately 5 minutes prior to discharge into a metal 5 gallon container. Two $16 \mathrm{oz}$ samples per batch were collected directly from the mixer discharge; one near the beginning of the pour and one near the end. Figure 6, showing grab samples from each of the eight batches, demonstrates the color variation observed in the final product, an indicator of the form of cinnabar created. 


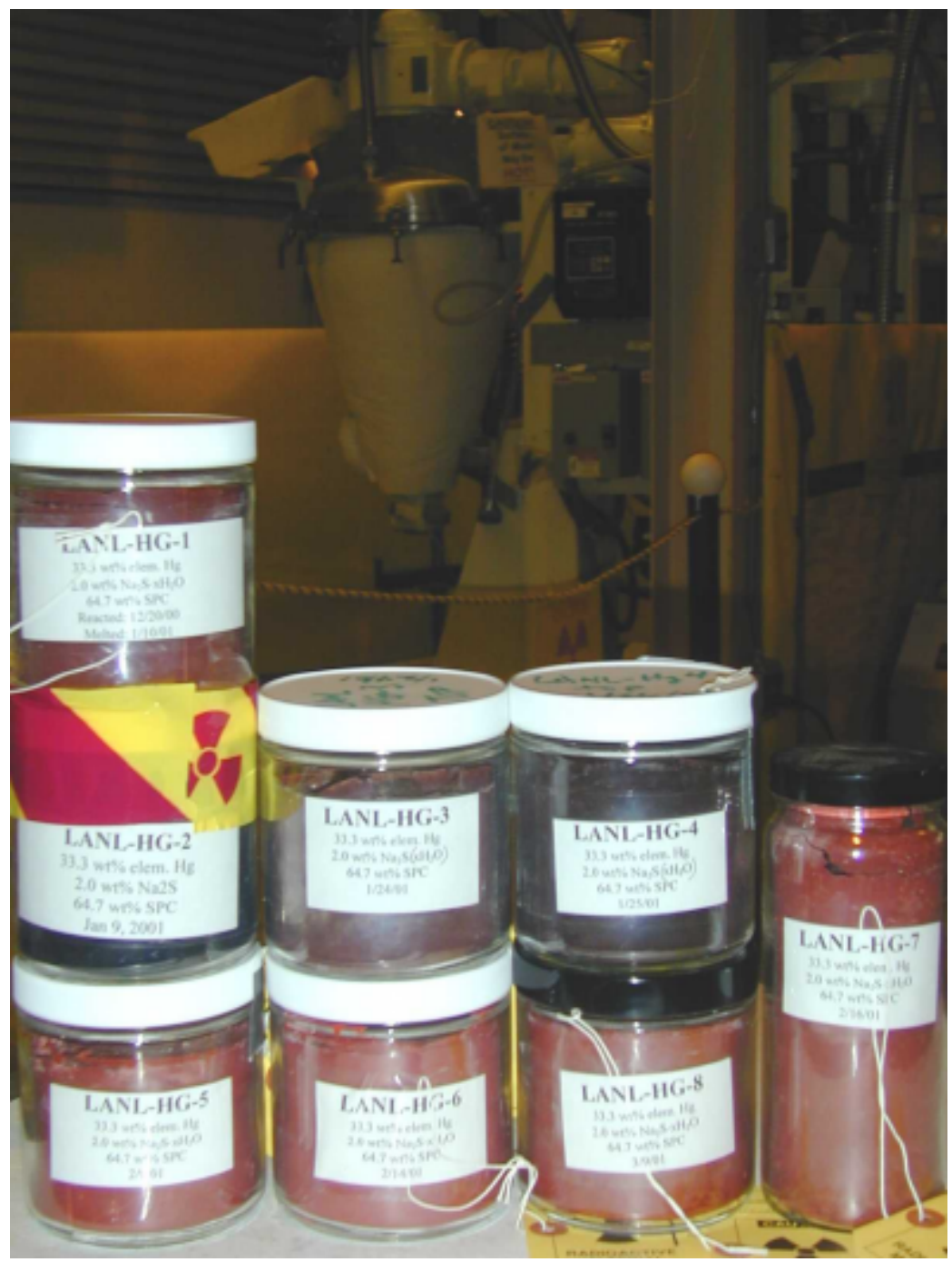

Figure 6. SPSS grab samples from LANL mixed-waste mercury process batches.

TCLP samples were made by remelting the $\sim 1 \mathrm{~kg}$ subsamples from each batch and pouring material into Teflon molds to create small pellets, approximately $8 \mathrm{~mm}(5 / 16$ ") diameter by $8 \mathrm{~mm}(5 / 16$ ") high, which meet the size requirement of the TCLP test while maintaining the integrity of the encapsulated product. Approximately 60-g from each subsample was then combined to form a composite (i.e., top and bottom) for each batch (Figure 7). Composite samples were shipped to Severn Trent Laboratories (Stamford, CT) for TCLP testing, in accordance with EPA SW-846.3-3, Method 1311. All tests were conducted using extraction fluid \#1 ( $\mathrm{pH} 4.93 \pm 0.05)$. 


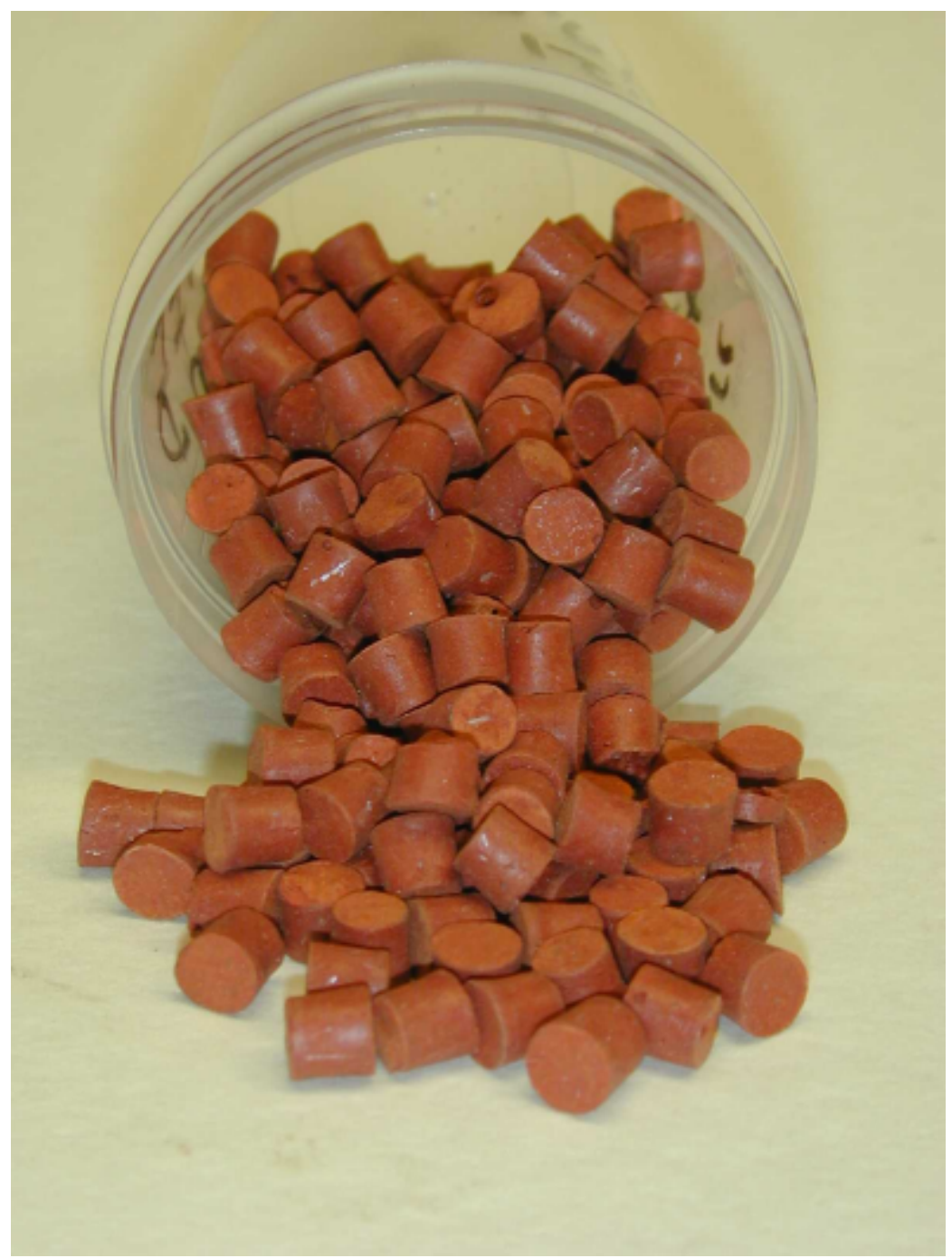

Figure 7. LANL Hg/SPSS pellets for TCLP testing.

TCLP results are presented in Table 4. Leach results for seven of the eight batches were below the TCLP limit of $200 \mathrm{ppb} \mathrm{Hg}$, while one batch met the more stringent Universal Treatment Standard (UTS) limit of 25 ppb. Not surprisingly, the highest test result was observed for Batch 1, where the mixer shaft had broken resulting in a shortened reaction time. Results for the other batches were unexpected, however, in light of prior pilot-scale treatment of BNL elemental mercury waste, where identical batch formulations yielded TCLP results one to two orders of magnitude lower. ${ }^{5}$ There appeared to be no significant difference between batches due to use of hydrated, versus dried form of additive. 
Table 4. TCLP Hg Results for SPSS Treated LANL Elemental Mercury Waste.

\begin{tabular}{|l|c|l|}
\hline Batch ID & TCLP Hg, ppb & \multicolumn{1}{c|}{ Comments } \\
\hline LANL-HG-1 & 527 & $\begin{array}{l}\text { Mixer shaft broke; } \\
\text { insufficient reaction time }\end{array}$ \\
\hline LANL-HG-2 & 70.7 & Used dried form of additive \\
\hline LANL-HG-3 & 46.0 & \\
\hline LANL-HG-4 & 41.1 & \\
\hline LANL-HG-5 & 85.1 & \\
\hline LANL-HG-6 & 24.6 & \\
\hline LANL-HG-7 & 116 & \\
\hline LANL-HG-8 & 44.1 & \\
\hline
\end{tabular}

Based on observations by Fuhrmann, et. al., ${ }^{4}$ and earlier BNL leach results for treated elemental mercury waste, it was suspected that the mercury/sulfur reaction kinetics are at play in the disparate results, where sulfur and mercury continue to react, even after stabilization, slowly forming more mercuric sulfide. Fuhrmann noted not only a 50-fold decrease in TCLP leachability on repeat testing after several months, but also significant reduction in mercury vapor concentration with time in the reaction vessel headspace. To test this theory, pelletized material composited from Batch 7, which originally yielded a TCLP concentration of 116-ppb Hg, was retested after 3 months storage in a sealed container. TCLP results for the repeat sample were indeed significantly reduced, to a value of $1 \mathrm{ppb}$. LANL personnel have noted similar reductions in mercury leachability and vapor pressure. ${ }^{7}$

\section{$\underline{4.2}$ Treatment of Contaminated Labware/Containers}

Glassware included/used in the LANL treatment was crushed for batch treatment/macroencapsulation. Glass bottles were placed into a 5 gallon drum and agitated using the paint shaker. Approximately twenty 1 " steel bearings were included to break up the assortment of bottles, vials, and tubes. As this process yielded pieces $>2$ " in size, the glass was further comminuted by impact with a 2" diameter steel ram. This process effectively reduced all glass pieces to $<1$ ". A photograph of this material is shown in Figure 8 . To react this waste, the crushed glass was then agitated with SPC powder and $0.5 \mathrm{wt} \%$ additive to stabilize residual mercury contamination, then heated to $135^{\circ} \mathrm{C}$ to melt and macroencapsulate the $\mathrm{HgS}$ and glass aggregate. Approximately $3.5 \mathrm{~kg}$ of waste was processed using a formulation of 60 -wt $\%$ crushed glass, 39.5-wt $\%$ sulfur polymer cement and $0.5 \mathrm{wt} \%$ additive. At this loading, the liquid SPC just covered the surface of the crushed glass bed volume (Figure 9). 


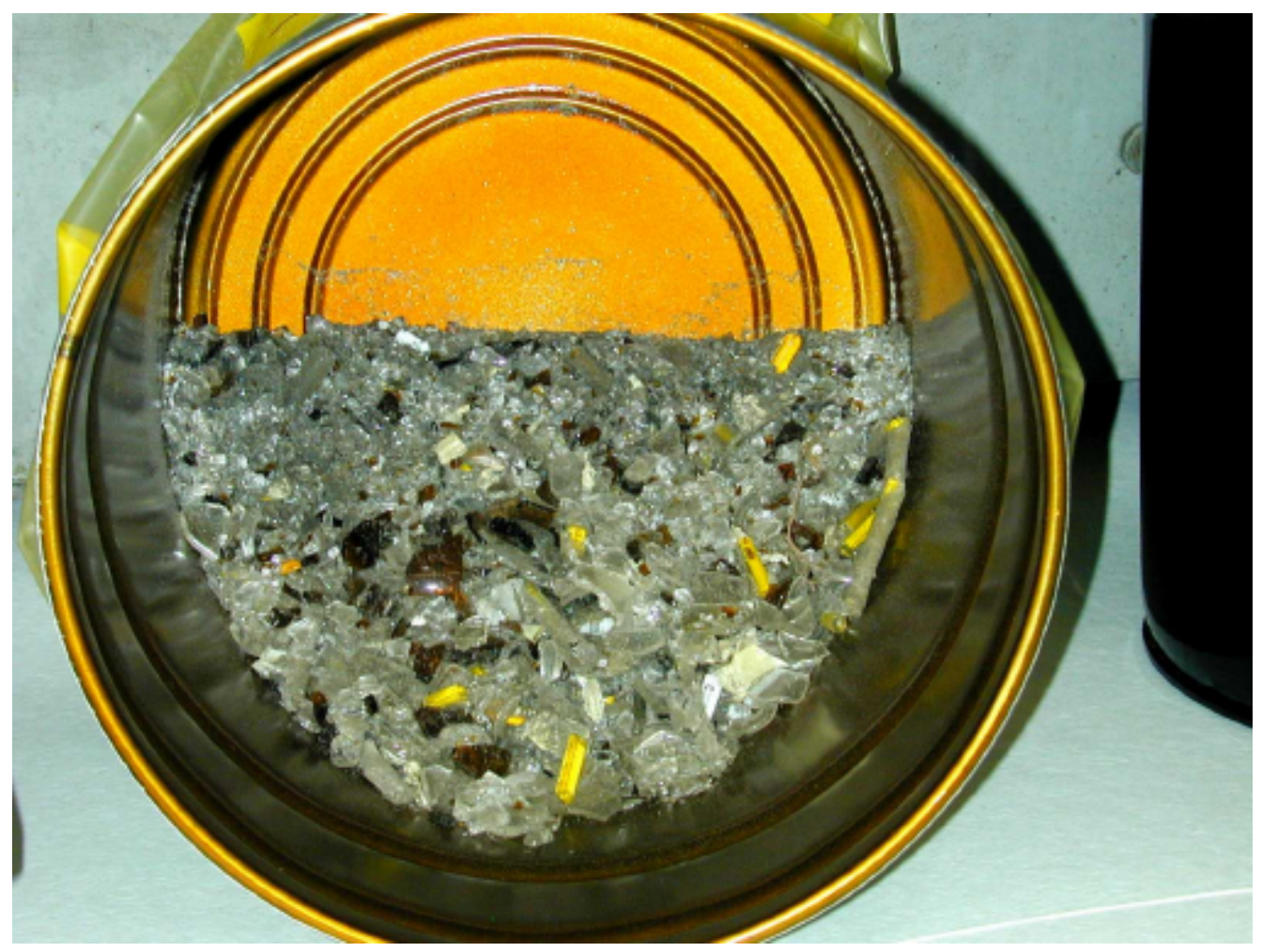

Figure 8. Crushed LANL glassware prior to SPSS treatment.

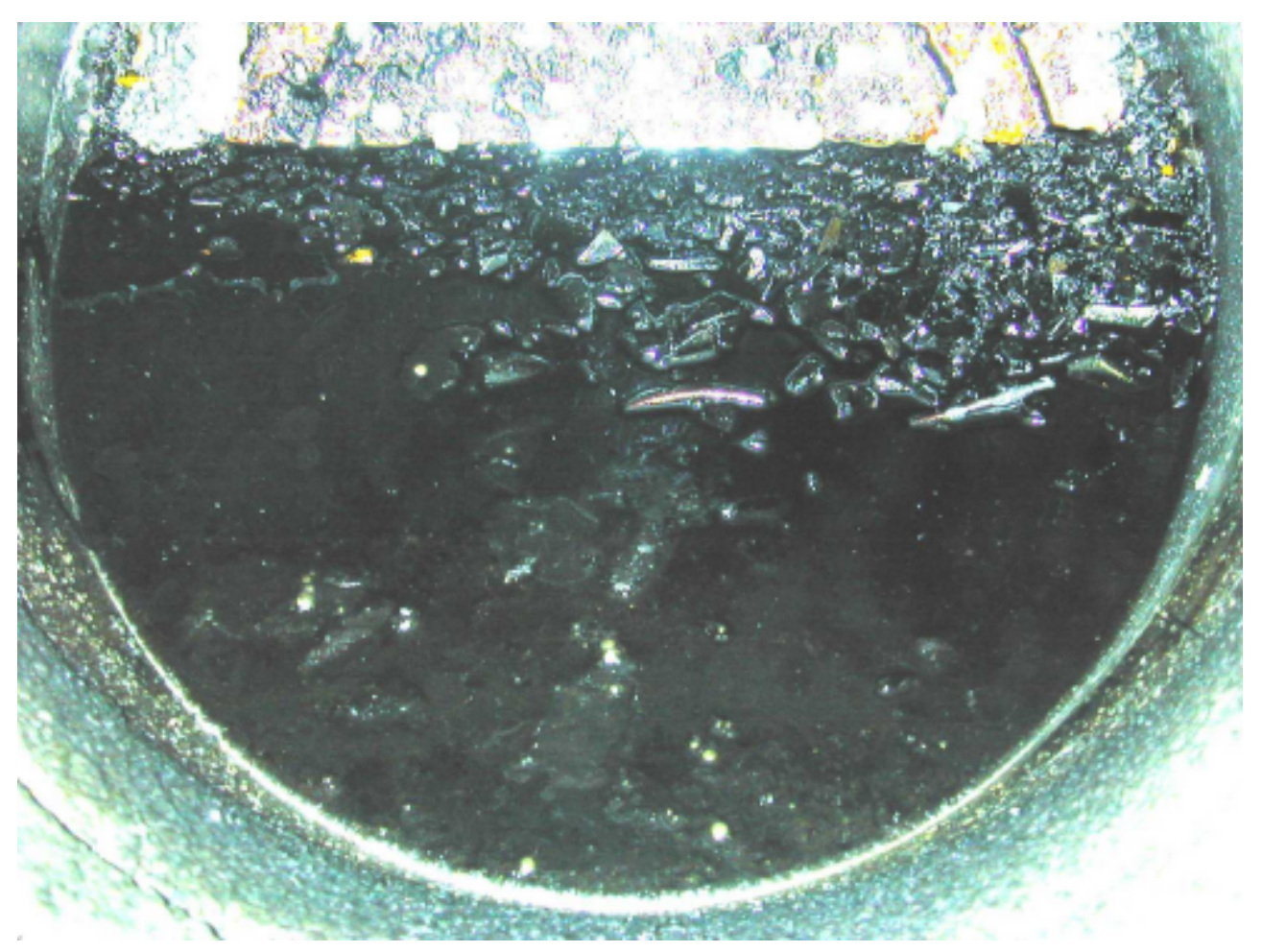

Figure 9. SPSS processed LANL glassware. 
Trial batches of low density and high-density polyethylene (LDPE and HDPE, respectively) were mixed with molten SPC $\left(135^{\circ} \mathrm{C}\right)$ to determine compatibility of shredded plasticware with the SPSS process. These plastics tended to fuse together in clumps and float on the surface of the molten SPC, especially HDPE that softened and fused into a single mass. LANL plastic containers were manually cut to a size of 1 to 1.5 inch (Figure 10) then placed into the large plastic carboy (Container ID\#C97094977) included with the shipment. $3 \mathrm{~kg}$ of powdered SPSS and $60 \mathrm{~g}$ of dried additive were added and the contents tumbled on a rolling mill for 12 hours (Figure 11). Concerned that heating the plastic carboy to melt the SPC would compromise its integrity, or addition of molten SPC to the carboy would not adequately melt its contents, the reacted plasticware was transferred to a metal 5 gallon drum and heated. As with trial batches, the plastic pieces floated to the surface of the molten SPC. This material was cooled to fix the plastic at the surface, then a 2" layer of neat molten SPC was poured on top of the SPSS product to macroencapsulate the plastic. Similarly, the carboy used to react the plasticware was filled to a height of 6" to encapsulate the residual material coating the walls of the vessel.

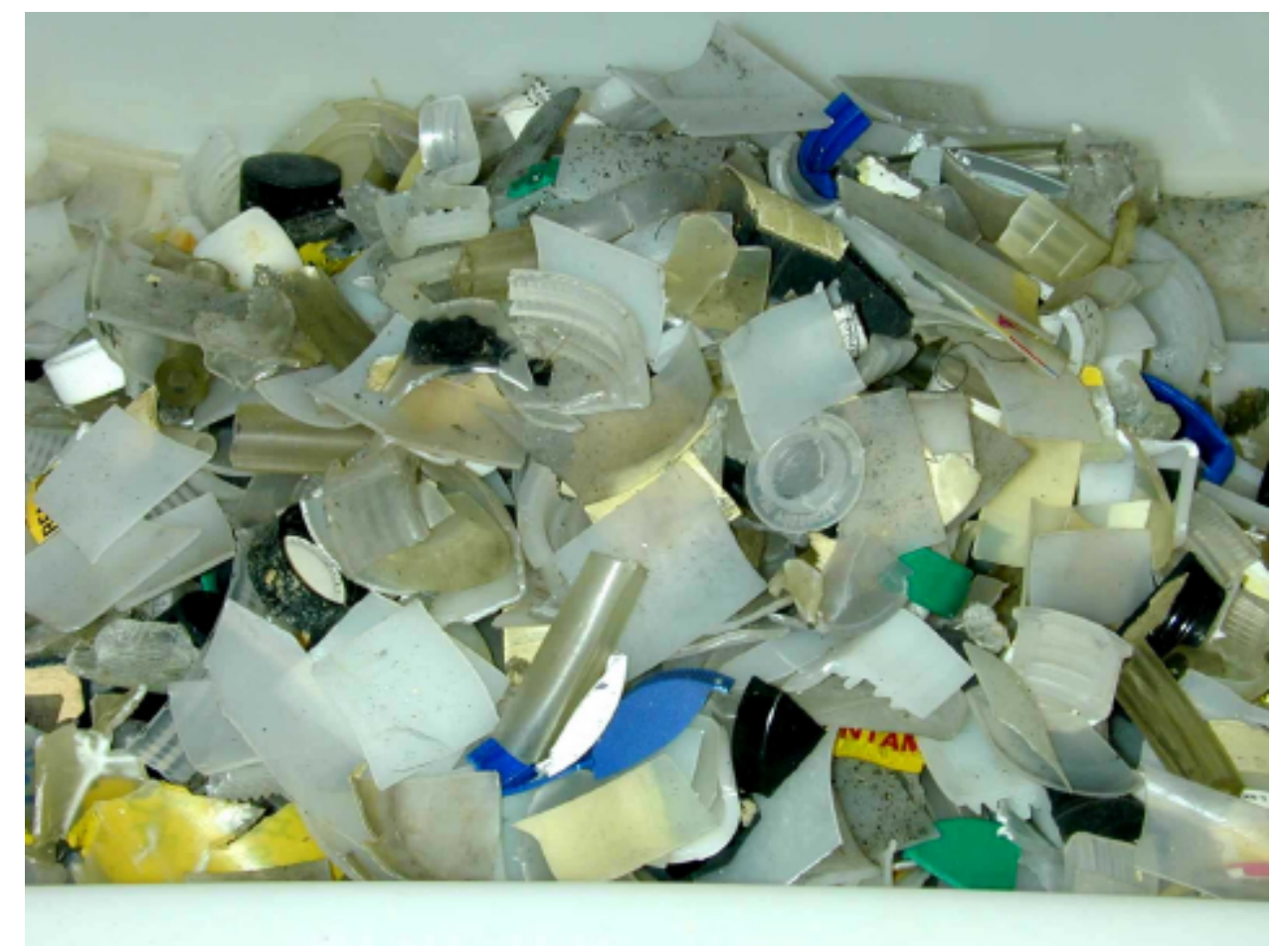

Figure 10. Size-reduced LANL plasticware. 


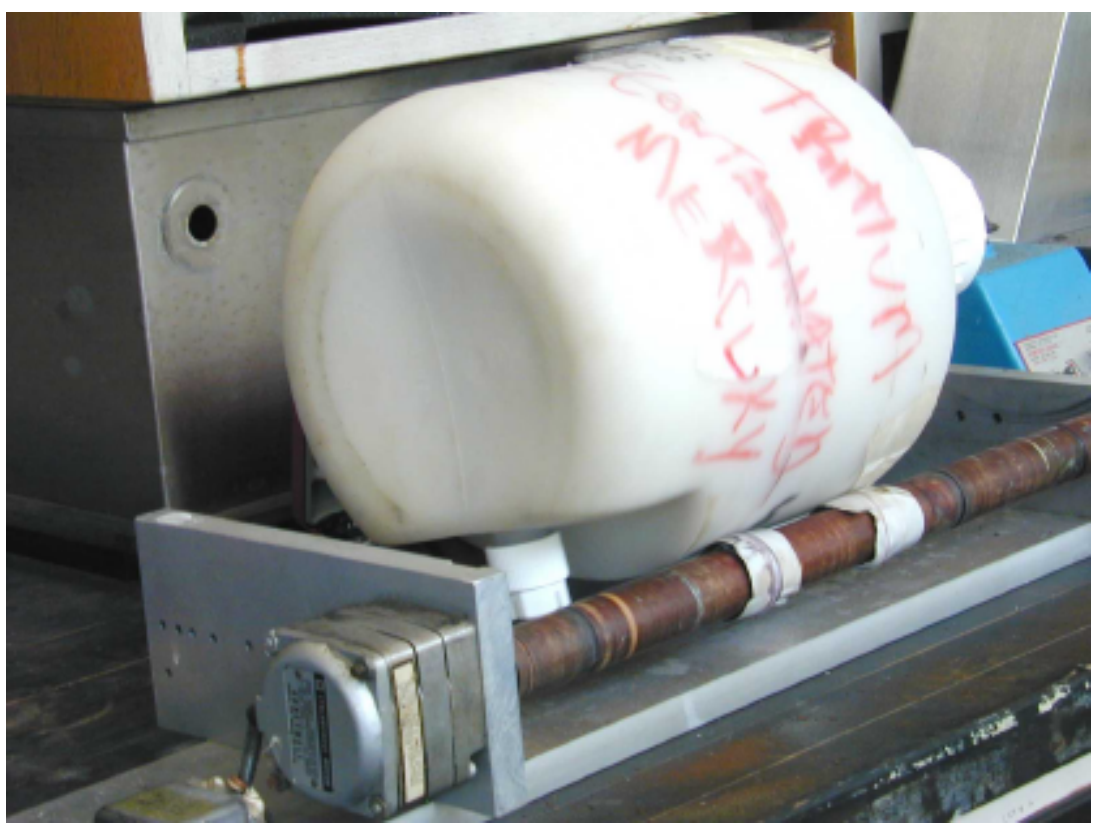

Figure 11. SPSS reaction of LANL plasticware.

Finally, LANL mercury flasks were SPSS treated by adding $1 \mathrm{~kg}$ of powdered SPC, $20 \mathrm{~g}$ dried additive, and 30-1/2 inch stainless steel bearings to each flask. The metal flasks were clamped in the paint shaker and agitated for 4 hours (Figure 12). With the contents reacted, the flasks were transferred to a lab oven to melt the SPC and encapsulate the mercury sulfide. Finally, as with the plastic carboy above, the flasks were topped off with neat molten SPC to macroencapsulate the SPSS product within each flask.

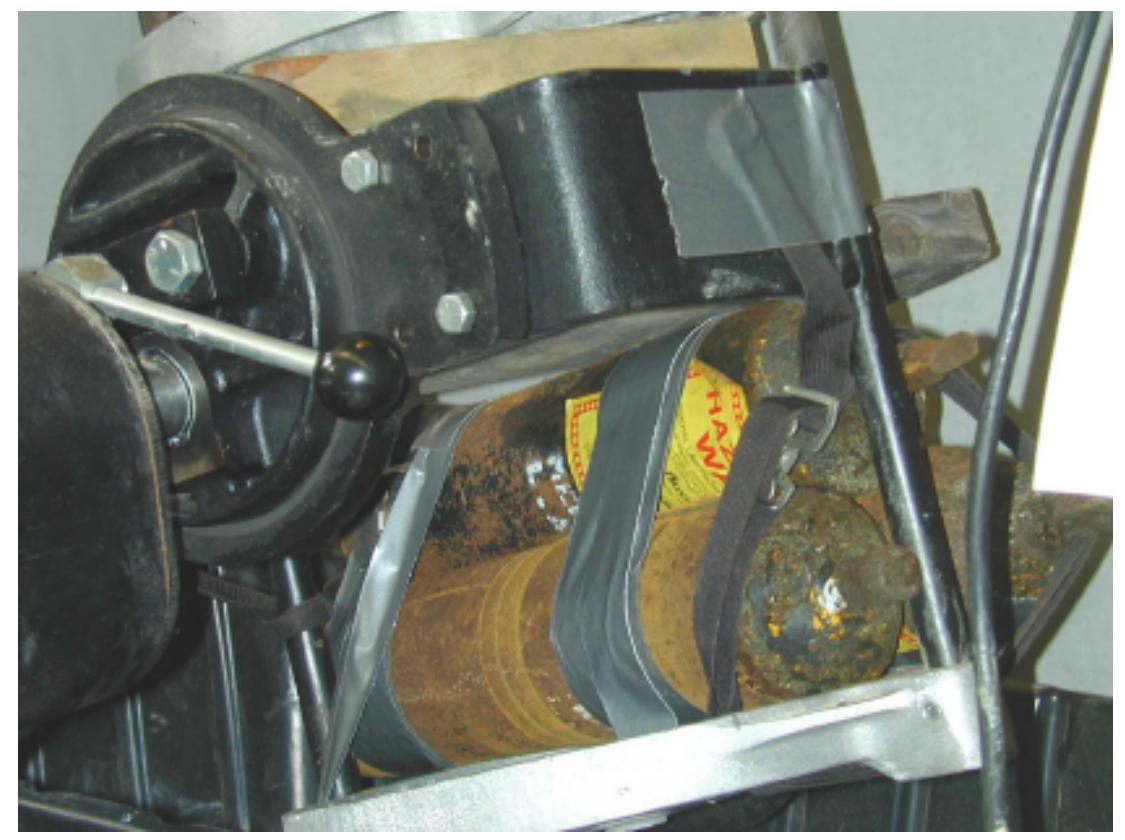

Figure 12. SPSS treatment of LANL mercury flasks. 


\section{DISCUSSION AND CONCLUSIONS}

SPSS is a cost effective, simple process to treat several difficult $\mathrm{Hg}$ streams. From a processing standpoint, SPSS effectively treated LANL mixed-waste elemental mercury at loadings up to 33-wt \%. Mercurycontaminated containers and mixed-waste debris were also effectively treated by SPSS macroencapsulation. These processes meet the current EPA standard of amalgamation for D009 waste containing elemental mixed-waste mercury. TCLP leachability, although not regulated for this treated waste, was below both TCLP and UTS threshold limits. Processing difficulties (e.g., equipment breakdown, pooling of mercury) may be readily overcome with equipment modifications or selection of alternate mixing techniques, and optimization of process parameters (e.g., tailoring of additives, real-time monitoring of reaction kinetics) may result in even higher waste loadings and increased process efficiency. As a result of BNL SPSS treatment results, EPA is investigating changes in $\mathrm{Hg}$ treatment requirements.

\section{ACKNOWLEDGMENTS}

The authors gratefully acknowledge the assistance provided by Avril Millensted at LANL for facilitating shipment of waste, coordinating project logistics, and providing guidance for this effort.

\section{REFERENCES}

1. Colombo, P., Kalb, P.D., Heiser, J. H. "Process for the Encapsulation and Stabilization of Radioactive, Hazardous and Mixed Wastes.” U.S. Patent 5,678,234, October 14, 1997.

2. Kalb, P.D., J.H. Heiser, R. Pietrzak, and P. Colombo, "Durability of Incinerator Ash Waste Encapsulated in Modified Sulfur Cement," Presented at the 1991 Incineration Conference: Thermal Treatment of Radioactive, Hazardous, Chemical, Mixed, and Medical Wastes, Knoxville, TN, May 1991.

3. Kalb, P.D., J.H. Heiser, and P. Colombo, "Modified Sulfur Cement Encapsulation of Mixed Waste Contaminated Incinerator Fly Ash,” Waste Management, Vol. 11, No. 3, pp. 147-153, Pergamon Press, 1991.

4. Fuhrmann, M, D. Melamed, P.D. Kalb, J.W. Adams, and L.W. Milian, “Sulfur Polymer Solidification/Stabilization of Elemental Mercury Waste,' BNL- ,

5. Kalb, P.D., J.W. Adams, and L.W. Milian, "Sulfur Polymer Stabilization/Solidification (SPSS) Treatment of Mixed-Waste Mercury Recovered from Environmental Restoration Activities at BNL," BNL-52614, January 2001.

6. US Environmental Protection Agency, Toxicity Characteristic Leaching Procedure (TCLP), 40 CFR Part 261, Appendix II, September 19, 1994.

7. Private Communication, Bryan Carlson, LANL, August 22, 2001. 